\title{
Rural versus Urban Areas and the Supplemental Nutrition Assistance Program
}

\author{
Senal A. Weerasooriya, and Jeffrey J. Reimer
}

Abstract

This study quantifies how spending changes induced by the Supplemental Nutrition Assistance Program (SNAP) affects production and employment in rural and urban areas. A general equilibrium simulation model with an estimated demand system is first used to project how SNAP affects spending on different goods and services. These impacts are then linked to the expansion and contraction of different economic sectors that differ in importance across rural and urban Oregon. In urban areas, a number of service sectors linked to higher-income households shrink slightly in response to SNAP, while food-related sectors expand; the net effect on jobs is slightly negative. Production changes in rural areas are generally smaller, while having a slightly positive net effect on jobs. Overall, SNAP makes a positive difference for low- or no-income households without strong effects elsewhere in the economy.

Keywords: Government programs, Nutrition assistance, Regional studies JEL Codes: E16, I38, Q18, R13

\section{Introduction}

The Supplemental Nutrition Assistance Program (SNAP), also known as the food stamp program, provides food purchasing assistance for low- and no-income individuals living in the United States. SNAP performs a countercyclical function for such households, allowing them to smooth their consumption across periods of instability. In abbreviated form, the mission of SNAP is "to increase food security and reduce hunger...in a way that supports American agriculture" (USDA FNS 2019). SNAP is therefore not just about enhancing nutrition for people in need; it is meant to have effects on certain parts of the U.S. economy.

Because it's a large federal program, there is political resistance to SNAP in some quarters due in no small part to its costs, which can be many billions of dollars per year. These politically controversial aspects have been examined

Weerasooriya is a lecturer in the Department of Agricultural Economics and Business Management, University of Peradeniya. Reimer is a professor in the Department of Applied Economics, Oregon State University. Correspondence: Jeff Reimer, Department of Applied Economics, Oregon State University, 213 Ballard Extension Hall, Corvallis, OR, 97331. Email: jeff. reimer@oregonstate.edu Phone: 541-737-1415

Agricultural and Resource Economics Review 49/3 (December 2020) 538-557

(C) The Author(s) 2019. This is an Open Access article, distributed under the terms of the Creative

Commons Attribution licence (http://creativecommons.org/licenses/by/4.0/), which permits unrestricted re-use, distribution, and reproduction in any medium, provided the original work is 
in a strand of the academic literature that considers SNAP's effects upon the U.S. economy as a whole (Hanson et al. 2002; Reimer and Weerasooriya 2019). These studies take into account taxpayers who help fund the program, economic sectors that expand or shrink as a result of SNAP, and consumers who face different wages and prices as a result of SNAP. For example, Reimer, Weerasooriya, and West (2015) found that SNAP increases the effective spending power of SNAP-eligible households by 5.5 percent while slightly reducing the spending power of higher-income households. In the economy as a whole, SNAP causes more to be spent on the food sectors and less to be spent on non-food sectors.

The above studies focused on the aggregate United States but left unconsidered whether there is any geographical significance to SNAP's impacts. There is reason to expect that the aggregate economic impacts of SNAP can vary across regions. The distribution of low- and high-income households may be uneven across the landscape, and the distribution of businesses whose sales are affected by SNAP may also be uneven.

While SNAP's market effects are likely to vary geographically, little work has been done in the literature. One important study has examined how the performance of local economies affects the need for SNAP (Klerman and Danielson 2016). Closer to this study, Pender et al. (2019) make an important contribution in linking SNAP benefits across rural and urban areas to changes in employment. They find that SNAP redemptions generally have a positive and statistically significant impact on county-level employment, although in some of the models there is a negative effect for urban counties. As will be shown below, this is not dissimilar to the ultimate findings of this study, even though the data and methodologies are distinct. Pender et al. (2019) regress changes in employment on SNAP redemptions, while this study fully models the linkages, including the intermediate effects on consumption and production by sector. It also simulates quantity and price changes for goods and services.

The goal of this study is to examine whether SNAP's various effects are systematically different across rural and urban areas, focusing on the production side of the economy, and on the state of Oregon. The analysis is restricted to this state because of the availability of data and since it is reasonably representative of many states, having one large city and several smaller urban areas. This study follows the Bureau of Economic Analysis (BEA) classification of metro and non-metro counties in determining urban and rural areas of Oregon.

A multiple market, general equilibrium approach is taken, since a potentially large number of sectors are impacted, including the agricultural and food sectors, as emphasized in the mission statement of SNAP. This simulation model approach serves a dual purpose of independently validating results of econometric analyses such as Pender et al. (2019) and shedding new light on the linkages between SNAP and jobs.

The analysis begins with construction of a social accounting matrix (SAM) that links the production of goods and services to the firms and people that 
buy them, while further linking them back to primary inputs (labor and capital) used in their production. The SAM embodies the effects of SNAP in the base year, so the structure of the economy in the absence of this program must be simulated. A counterfactual scenario is therefore constructed that intentionally represents a situation that did not occur. This is done with the general equilibrium model. Predicted values from this scenario are then compared to the baseline SAM data.

The above methodology is similar to earlier work by Reimer, Weerasooriya, and West (2015), but this study uses data that are more disaggregated in two significant ways. First, instead of dividing the U.S. economy into only six sectors, this study distinguishes 35 . Second, this study has information on these sectors by rural and urban orientation. Additional contributions are to estimate changes in the number and location of jobs.

Another distinctive feature is to estimate consumer demand functions for the relevant households using consumer expenditure survey data. The simulation model therefore has an improved characterization of how households allocate their overall spending upon receiving SNAP benefits.

A preview of the results is as follows. Urban SNAP-receiving households are estimated to experience an increase in effective disposable income of $\$ 2,815$, while rural SNAP-receiving households experience an increase of $\$ 3,349$ per year in disposable income. This is mainly due to larger average household size in rural areas, with the residual explained primarily by factor market effects. Increased disposable income is spent on items allowable under SNAP, yet frees up disposable income for spending on other products, leading to changes elsewhere in the economy. The economic sectors of urban areas experience both the largest expansions and largest declines associated with SNAP. For example, jobs in the farming sector increase by 391 in rural areas and by 506 in urban areas. As resources are pulled into the food industries, there is a slight decline in labor-intensive industries such as wholesale, retail, health, financial, and insurance services. Urban economies are oriented relatively more towards these services, and as a result, labor employment falls slightly in urban areas. On net, SNAP is estimated to cause a net loss of 433 jobs in urban areas and a net gain of 354 jobs in rural areas.

The overall results are consistent with the study's hypotheses that SNAP has a variety of place-based effects. However, the net job effects are very small in a state that is estimated to have 2,188,001 jobs. The salient point that emerges is that SNAP greatly changes the spending of households that use it without adversely affecting other households and other parts of the economy.

The remainder of the paper is as follows. The next section provides a methodological overview and describes the data compiled for the study. The subsequent sections describe the model and counterfactual scenario. Subsequent sections report the results and then summarize the limitations, policy implications, and conclusions of the study. 


\section{Data}

A SAM was created using primarily IMPLAN (2012) data that detail the structure of income and product accounts for 2011. The SAM quantifies flows of expenditures across multiple agents in the regional economy. While 440 sectors are distinguished, sectors of lesser importance are aggregated such that in the end, 35 economic sectors are examined. The sectors are reported in Table 1 and encompass both food and non-food sectors.

There is no universal classification of regions into "rural" and "urban" in the literature, but for this study the Bureau of Economic Analysis's (2019) metro/ nonmetro classification of Oregon's counties was employed. Of the 36 counties, 23 were categorized as urban, with the remaining 13 being rural. A review of these data show that shares of employment, output, and household income are generally larger in urban counties. One exception is agricultural output, which at $\$ 3,795$ million in rural areas exceeds that of urban counties $(\$ 3,347$ million), despite the fact that rural counties have less than 17 percent of the state's population. Food and beverage output, by contrast, is much larger in urban areas $(\$ 12,138$ million) than in rural areas $(\$ 3,369$ million).

Table 2 reports a number of descriptive statistics about the regional economy. For example, the GDP (gross domestic product) of Oregon is \$166,122 million, which is approximately 1.1 percent of the U.S. national GDP. Rural households received approximately 10 percent of all household income received in the state, which was $\$ 186,959$ million for the state as a whole. Against this, the amount of SNAP funds disbursed in the state was $\$ 1,189$ million or 0.72 percent of state GDP. Rural counties absorbed approximately $\$ 274$ million of SNAP funds (23 percent), while urban counties absorbed $\$ 916$ million (77 percent). Other parts of Table 2 will be discussed in the results section below.

The population of Oregon is 3.87 million, with 3.22 million living in urban counties and 0.65 million living in rural counties. For this study, the population is grouped into four households distinguished by whether they are eligible for SNAP and are rural or urban. Data sources include IMPLAN (2012), USDA FNS (2019), USDA ERS (2019), and the U.S. Census Bureau (2019). To be considered eligible for SNAP benefits, a household must have a gross income at or below 130 percent of the poverty line. For 2011, that corresponded to an annual income of about $\$ 24,100$ for a household of three (CBPP 2016). On this basis, it was assumed that IMPLAN household categories 1-3, which correspond to households with incomes between $\$ 0$ and $\$ 25,000$, are SNAP eligible. IMPLAN household categories 4-9, which have incomes exceeding $\$ 25,000$, are considered SNAP ineligible and are sometimes referred to as Non-SNAP households below.

Note that eligibility does not imply participation, as some eligible households do not participate in SNAP even when they are eligible (USDA FNS 2019). This distinction is fairly minor in the case of Oregon since the participation rate among SNAP-eligible Oregonians exceeds 94 percent (USDA FNS 2014). The 
Table 1. Economic Sectors

\begin{tabular}{|c|c|c|c|}
\hline \multirow[b]{2}{*}{$\#$} & \multirow[b]{2}{*}{ Category } & \multicolumn{2}{|c|}{ Expenditure elasticities } \\
\hline & & $\begin{array}{l}\text { SNAP } \\
\text { households }\end{array}$ & $\begin{array}{l}\text { Non-SNAP } \\
\text { households }\end{array}$ \\
\hline 1 & Crop farming & $0.514^{*}$ & 0.253 \\
\hline 2 & Animal farming & $0.771^{*}$ & 0.649 \\
\hline 3 & Ag chemicals and services & 1.795 & 1.309 \\
\hline 4 & Forestry and mining & 1.795 & 1.309 \\
\hline 5 & Processed food animal origin & $0.771^{*}$ & 0.649 \\
\hline 6 & Processed food plant origin & $0.514^{*}$ & 0.253 \\
\hline 7 & Processed food other & $1.420^{*}$ & 0.882 \\
\hline 8 & Food away from home & 0.778 & 0.655 \\
\hline 9 & Alcohol and tobacco & 1.325 & 0.839 \\
\hline 10 & Crude oil, natural gas, coal & 1.399 & 1.098 \\
\hline 11 & Apparel and textiles & 0.967 & 0.965 \\
\hline 12 & Refined petroleum products & 1.364 & 0.960 \\
\hline 13 & Chemicals, rubber, plastic & 1.364 & 0.960 \\
\hline 14 & Iron other metal manufacturing & 1.364 & 0.960 \\
\hline 15 & Computer manufacturing & 1.364 & 0.960 \\
\hline 16 & Electric goods manufacturing & 1.364 & 0.960 \\
\hline 17 & Machinery/equipment manufacturing & 1.364 & 0.960 \\
\hline 18 & Motor vehicles manufacturing & 1.364 & 0.960 \\
\hline 19 & Household manufacturing and services & 1.364 & 0.960 \\
\hline 20 & Other non-durable manufacturing & 1.364 & 0.960 \\
\hline 21 & Other durable manufacturing & 1.364 & 0.960 \\
\hline 22 & Construction & 1.074 & 1.066 \\
\hline 23 & Transportation & 1.211 & 1.153 \\
\hline 24 & Wholesale trade & 1.088 & 1.136 \\
\hline 25 & Retail trade & 1.088 & 1.136 \\
\hline 26 & Finance and insurance & 1.214 & 1.343 \\
\hline 27 & Housing real estate & 1.074 & 1.066 \\
\hline 28 & Education & 1.040 & 1.249 \\
\hline 29 & Health & 1.040 & 1.249 \\
\hline 30 & Electric utilities & 1.399 & 1.098 \\
\hline 31 & Gas utilities & 1.399 & 1.098 \\
\hline 32 & Other utilities & 1.211 & 1.153 \\
\hline 33 & Business-related services & 1.214 & 1.343 \\
\hline
\end{tabular}


Table 1. Continued

\begin{tabular}{llcc}
\hline & & \multicolumn{2}{c}{ Expenditure elasticities } \\
\cline { 3 - 4 }$\#$ & Category & $\begin{array}{l}\text { SNAP } \\
\text { households }\end{array}$ & $\begin{array}{c}\text { Non-SNAP } \\
\text { households }\end{array}$ \\
\hline 34 & Personal services & 1.795 & 1.309 \\
35 & Other services & 1.214 & 1.343 \\
\hline $\begin{array}{l}\text { Note: Expenditure elasticities are from the econometric estimation detailed in the study, Muhammad et } \\
\text { al. (2011) and Reimer and Hertel (2004). Asterisk }\left({ }^{*}\right) \text { denotes food categories for which the elasticity is } \\
\text { adjusted to account for observed changes in food spending under SNAP according to evidence on } \\
\text { additionality. }\end{array}$
\end{tabular}

Table 2. Additional statistics and results

\begin{tabular}{llll}
\hline Variable & Oregon & $\begin{array}{l}\text { All rural } \\
\text { counties }\end{array}$ & $\begin{array}{c}\text { All urban } \\
\text { counties }\end{array}$ \\
\hline $\begin{array}{l}\text { Gross domestic product (\$ million) } \\
\text { Share of U.S. economy (\%) }\end{array}$ & 166,122 & 19,393 & 146,729 \\
$\begin{array}{l}\text { Income received by households } \\
\quad \text { \$ million) }\end{array}$ & 1.1 & 0.13 & 0.97 \\
$\begin{array}{l}\text { Income received by households (\%) } \\
\text { SNAP received (\$ million) }\end{array}$ & 100.00 & 9.98 & 168,308 \\
$\begin{array}{l}\text { SNAP benefits as share of state } \\
\quad \text { economy (\%) }\end{array}$ & 0.72 & 274 & 90.02 \\
$\begin{array}{l}\text { Base value of output (sales in \$ million) } \\
\text { Estimated change in value of output due }\end{array}$ & $316,548.9$ & $36,953.0$ & 916 \\
$\quad$ to SNAP (\$ million) & 209.9 & 24.5 & 0.55 \\
$\begin{array}{l}\text { Estimated change in value of output per } \\
\quad \text { dollar of SNAP (\$) }\end{array}$ & 0.18 & 0.16 & 185.4 \\
$\begin{array}{l}\text { Base number of jobs (full or part time) } \\
\text { Estimated change in number of jobs due } \\
\quad \text { to SNAP }\end{array}$ & $2,188,001$ & 339,740 & $1,848,261$ \\
$\begin{array}{l}\text { Estimated change in employment due to } \\
\quad \text { SNAP (\%) }\end{array}$ & -0.004 & 0.104 & -433 \\
\hline
\end{tabular}

Sources: USDA FNS (2019), IMPLAN (2012), and model predictions. Some values may not sum perfectly due to rounding.

analysis can be done according to eligibility or participation; the former was chosen for reporting below.

Table 3 reports demographic information for the four types of households modeled in the study. There were 70,260 and 201,417 SNAP-receiving households in rural and urban areas, respectively, and 334,772 and 959,710 
Table 3. SNAP and Oregon

\begin{tabular}{lcccr}
\hline & $\begin{array}{c}\text { Rural SNAP } \\
\text { households }\end{array}$ & $\begin{array}{l}\text { Urban SNAP } \\
\text { households }\end{array}$ & $\begin{array}{l}\text { Rural } \\
\text { Non-SNAP } \\
\text { households }\end{array}$ & $\begin{array}{l}\text { Urban } \\
\text { Non-SNAP } \\
\text { households }\end{array}$ \\
\hline Number of persons & 151,561 & 501,770 & 607,047 & $2,611,481$ \\
Number of households & 70,260 & 201,417 & 334,772 & 959,710 \\
Average persons per household & 2.2 & 1.8 & 2.5 & 2.7 \\
\hline
\end{tabular}

Source: USDA FNS (2019), IMPLAN (2012), and related sources.

non-SNAP households in rural and urban areas, respectively. Table 3 suggests that rural populations tend to have a greater need for and use of SNAP; approximately one in five rural residents are eligible for SNAP while one in six urban residents are eligible for SNAP.

One additional source of data is consumer expenditure survey data collected from Bureau of Labor Statistics Public-Use Micro Data. They are used to estimate expenditure elasticities as described below.

\section{Model}

In order to gauge impact, the analysis will compare a simulated, non-SNAP scenario to the observed SAM baseline that incorporates the actual effects of SNAP. The non-SNAP scenario is simulated with a general equilibrium model that incorporates optimizing households and firms, intermediate input use, government transfers, savings and investment, and trade with the rest of the world. The model is similar to that of Löfgren, Robinson, and Harris (2002) and Holland, Stodick, and Devadoss (2010) with some important differences described below. Since the model is documented in those studies, only its salient features are summarized below.

The model traces every dollar spent by all the agents of the economy and represents those agents as responding to changes in the economic environment. Each sector $i$ (alternatively indexed as $j$ ) is represented by a firm that maximizes profits given technology represented by a nested structure in which primary inputs (labor and capital) and intermediate inputs are combined via a constant elasticity of substitution (CES) technology. The primary and intermediate input nests are characterized with CES and fixed proportion technologies, respectively. This implies that as demand for different industries changes (as with SNAP), there is not just a fixed change in the use of inputs, as might be the case with input-output or SAM models. Rather, firms are assumed to minimize costs under the new situation. One of the measures of interest is demand for labor (jobs) versus capital. Flexibility between these two factors of production is represented in the following 
equation:

$$
Y_{i}=\frac{\theta_{i}}{1-t v a_{i}-\sum_{j} i c a_{i j}}\left(\sum_{f} \delta_{f i} F_{f i}^{-\rho_{i}}\right)^{-\frac{1}{\rho_{i}}},
$$

where $Y_{i}$ is output of good $i, \theta_{i}$ is a production shift parameter, tva is value added tax, ica is the quantity of good $i$ used in good $j, F_{f i}$ is the quantity of factor $f$ demanded for good $i, \delta_{f i}$ is a share parameter, and $\rho$ is the CES parameter. Both $i$ and $j$ are indexed $i, j=1, \ldots, 35$.

There is also flexibility on the consumption side. Households maximize StoneGeary utility, which yields final demand functions given by a linear expenditure system. This system was estimated as part of this study, so it is represented here in the econometric form that was used to generate the parameters:

$$
w_{i}=\gamma_{i} \frac{p_{i}}{m}+\beta_{i}\left(1-\frac{\sum_{j} p_{j} \gamma_{j}}{m}\right)+\sum_{r} \theta_{i r} Z_{r}+\mu_{i},
$$

where $i$ and $j$ are used to index the goods, $w_{i}$ is the budget share of good $i, p_{i}$ is the price of good $i, m$ is the total expenditure, $\beta_{i}$ is the marginal budget share of good $i$, and $\gamma_{i}$ is the subsistence level for good i. $Z_{r}$ represents demographic characteristic $r$, which in the empirical application includes family size, number of children, rural or urban location, housing type, and housing tenure. In addition, dummy variables were used to represent year and region. The unknown parameters to be estimated consist of $\beta_{i}, \gamma_{i}$, and $\theta_{i r}$ The error terms are $\mu_{i}$ and are assumed to be jointly normal and independent over observations, with zero mean and a constant covariance matrix. Since the model is nonlinear in these parameters, nonlinear seemingly unrelated regression was used. The restrictions $\sum_{i} \beta_{i}=1$ and $\beta_{i}>0$ were imposed to ensure the adding up property of demand systems. The expenditure elasticity for good $i$ and household $h$ is calculated as $\varepsilon_{i h}=\beta_{i} / w_{i h}$, where $h=$ SNAP and non-SNAP households, and $w_{i h}$ is the mean expenditure on good $i$ by household $h$.

The demand system was estimated for nine expenditure categories based on 4,296 observations from the Bureau of Labor Statistics Consumer Expenditure Survey. Annual incomes of the consumer units in the sample ranged from less than $\$ 5,000$ to more than $\$ 150,000$. While the complete set of results is not presented due to space constraints, the expenditure elasticities are reported in Table 1. Some of the 35 potential categories of consumption have a common estimate since they could not be uniquely identified from the nine categories of the demand system.

Other parameters of the model were calibrated using the regional SAM developed for the study. The model contains a small number of additional exogenous parameters that are set to values for which there is econometric 
evidence or for which there is a consensus in the literature (Waters, Holland, and Weber 1997; Löfgren, Robinson, and Harris 2002; McCullough et al. 2011).

The model is adapted to the four representative households described above. They receive income from labor, capital, and transfers and make expenditures on goods, services, transfers, taxes, and investment. Regional firms use labor, capital, and intermediate goods to maximize profits using constant returns to scale production technology. The state government collects taxes and receives transfers from other institutions, with spending constrained to equal revenue. Results obtained from the model are for the state as a whole and are decomposed based on the top-down shared approach (e.g., Bernat and Hanson 1995), a reasonable approximation when the regions are well integrated, as arguably is the case in this study.

Since the model makes use of IMPLAN employment data by sector, the model can directly calculate actual numbers of jobs. The value of capital and labor supplied to the market is assumed to equal the income earned from those factors by households. The net change in jobs need not equal zero, however, because the model allows that different sectors may pay different wages and have different labor productivity. The model allows that labor may move across sectors. The factor demand equations are given as:

$$
\tau_{f i} w_{f}=\frac{p v a_{i} \theta_{i}}{1-t v a_{i}-\sum_{j} i c a_{i j}}\left(\sum_{f f} \delta_{f f i} F_{f f i}^{-\rho_{i}}\right)^{-\frac{1}{\rho_{i}}-1} \delta_{f i} F_{f i}^{-\rho_{i}-1},
$$

where both $f$ and $f f$ index labor and capital, $w_{f}$ is the rental rate for factor $f, F_{f f i}$ is the quantity of factor $f$ demanded for good $i, \tau_{f i}$ is a wage distortion factor, and $p v a_{i}$ is the value-added price for good $i$. Employment changes will be an important measure of SNAP's impacts and are measured via (3).

The model has other equations imposing equilibrium in the market for goods, capital, and labor. To ensure that the model satisfies Walras' Law, a variable called WALRAS is added to aggregate market balance equations. A non-zero value of WALRAS guarantees that the total value of goods and money supplied equals that of goods and money demanded. The approach follows general equilibrium conventions (Löfgren, Robinson, and Harris, 2002).

As an improvement on Reimer, Weerasooriya and West (2015), the model of this study is modified to account for the fact that SNAP is an in-kind transfer where benefits are administered via electronic benefit transfer (EBT) accounts. These have the effect of restricting recipients to purchase eligible food and beverage items, as well as food-producing plants and seeds. Associated with this is the concept of "additionality," which is the amount by which a dollar of program spending results in additional food spending (Levedahl 1995, Barrett 2002, Hanson and Oliveira 2009). Additionality is an index ranging from 0 to 1 . A SNAP additionality of zero would imply that all food purchased under SNAP would have been purchased in any case with the 
participants' own money if SNAP were not in place. As such, SNAP would have no effect on food expenditure; the amount of money previously spent on food would now be spent on other goods and services, or be saved. At the other extreme, additionality of one implies that food expenditures rise by the full amount of SNAP benefits. In this case, SNAP would be very influential on food expenditure. A review of econometric evidence suggests the additionality associated with SNAP is approximately 0.3 , that is, 30 cents more food is purchased overall for every additional dollar of SNAP benefits distributed to the population (Breunig and Dasgupta 2005; Hanson and Oliveira 2009; Beatty and Tuttle 2015; Cuffey, Beatty, and Harnack 2016). Expenditure elasticities for SNAP were calibrated such that the model replicates this evidence (Table 1 ).

\section{Baseline Scenario and Experimental Design}

The model is represented by a simultaneous system of nonlinear equations written in the General Algebraic Modeling System (GAMS) software and solved using the PATH nonlinear solver. It is first run for the purpose of calibration, that is, to determine the values of certain parameters for which econometric evidence is unavailable. The SNAP experiment is then run to generate a prediction regarding what the economy would have been without SNAP in place.

In addition to the behavioral characterizations described elsewhere, this counterfactual scenario was carried out by changing a federal income tax/ transfer parameter within the model, denoted ty. This parameter represents the percentage of income that households pay to (or receive from) the federal government. It is initially calibrated such that the model replicates the detailed information about taxes and transfers embedded in the SAM. These taxes and transfers are for the federal government non-defense spending account and therefore do not represent taxes to other government accounts such as the federal government defense account or the state government accounts. The federal government non-defense account was chosen because it is where SNAP expenditures are embedded in the SAM.

In the baseline, the value corresponding to the federal government nondefense account for all SNAP households is $-\$ 305$ million, with a corresponding calibrated tax rate of $t y=-1.66$ percent (the negative value signifying that a net transfer from the government occurs for these households). To simulate the absence of SNAP, SNAP households are made to incur a tax rate of ty $=4.80$ percent. They might still receive transfers from government in other forms, but the net effect is to increase their payroll or income taxes (which are not distinguished within the model). Solving for the model's endogenous variables under this change to ty provides a counterfactual scenario in which SNAP was not in place.

To address concerns about the possible financial burden of SNAP, an additional scenario was considered that accounts for potential funding 
requirements of SNAP. In addition to the change in ty that simulates an elimination of SNAP, in this additional scenario taxpayers were relieved of some of the taxes they have to pay. In the SAM, the value of the relevant tax/ transfer account corresponding to all taxpayers was $\$ 10,328$ million, with a corresponding tax rate of $t y=6.94$ percent. If taxpayers would no longer pay the equivalent of what SNAP costs for the regions of interest, there would only be $\$ 9,657$ million of transfers to the federal government, with a corresponding tax rate of $t y=6.49$ percent. This second scenario therefore includes different changes to ty depending on income level and whether a household received SNAP funds or not.

Upon investigation, the results of this second scenario turned out to be very similar to the primary scenario of the study (in which SNAP is considered without imposing any assumption about funding). There were some differences in the results. For example, when the impact of SNAP is estimated assuming that new taxes are required to fund it, then federal government revenue and spending rises by 0.05 percent and 0.04 percent, and the size of the state economy (GDP) rises very slightly as well. Yet these and other effects throughout the economy were extremely minor. As a result, the results discussed below concern only the impact of SNAP without imposing any hypothetical assumptions about funding.

\section{SNAP's Effects on Consumption}

Results are reported in a way that is intended to be the most intuitive; they represent the change from not having SNAP (the model's counterfactual prediction) to having SNAP (as represented in the 35 sector, four-household SAM). Consumption impacts are first considered. Addressing this issue requires considering changes in how households spend their money once the program is introduced. These changes are driven by how SNAP funds can be spent and by the linear expenditure system for each household that allocates spending according to own-price, cross-price, and expenditure elasticities of demand.

Table 4 presents the changes in consumption expenditure on a per household level for the four household types. SNAP households increase their spending on food purchased for consumption at home (which can be purchased with SNAP benefits) by $\$ 912$ in rural areas and $\$ 766$ in urban areas. SNAP households increase expenditure over all other categories as well. This is consistent with econometric evidence in the literature such as Kim (2016), and happens because some personal funds (from wages or other income) that used to be allocated for food can now be allocated to other sectors according to the estimated household demand characterization of the model.

Table 4 shows that SNAP households increase spending on wholesale and retail services (by $\$ 242$ for rural households and $\$ 203$ for urban households), health services (by $\$ 429$ for rural households and $\$ 361$ for urban households), and housing (by $\$ 337$ for rural households and $\$ 283$ for 
Table 4. Changes in Consumption Expenditure under SNAP (\$ per Household)

\begin{tabular}{|c|c|c|c|c|}
\hline & $\begin{array}{l}\text { Rural SNAP } \\
\text { households }\end{array}$ & $\begin{array}{l}\text { Urban SNAP } \\
\text { households }\end{array}$ & $\begin{array}{l}\text { Rural } \\
\text { Non-SNAP } \\
\text { households }\end{array}$ & $\begin{array}{l}\text { Urban } \\
\text { Non-SNAP } \\
\text { households }\end{array}$ \\
\hline Food at home & 912 & 766 & -29 & -32 \\
\hline Dairy, eggs, meat and seafood & 350 & 294 & -11 & -12 \\
\hline $\begin{array}{l}\text { Grains, legumes, fruit and } \\
\text { vegetables }\end{array}$ & 244 & 205 & -3 & -3 \\
\hline Miscellaneous food & 318 & 267 & -15 & -16 \\
\hline Food away from home & 63 & 53 & -26 & -29 \\
\hline Non-food consumption & 2,376 & 1,997 & -937 & $-1,023$ \\
\hline Alcohol and tobacco & 34 & 29 & -9 & -10 \\
\hline Clothing & 26 & 22 & -13 & -14 \\
\hline Durables & 129 & 108 & -29 & -31 \\
\hline Non-durables & 136 & 114 & -48 & -53 \\
\hline Petroleum products & 73 & 61 & -21 & -23 \\
\hline Utilities & 157 & 132 & -43 & -47 \\
\hline Finance and Insurance & 153 & 128 & -105 & -115 \\
\hline Housing & 337 & 283 & -135 & -148 \\
\hline Health & 429 & 361 & -180 & -197 \\
\hline Education & 100 & 84 & -30 & -32 \\
\hline Transportation & 61 & 51 & -21 & -23 \\
\hline Services & 399 & 335 & -152 & -166 \\
\hline Wholesale and retail & 242 & 203 & -147 & -161 \\
\hline Miscellaneous & 100 & 84 & -3 & -3 \\
\hline Total consumption & 3,351 & 2,817 & -992 & $-1,083$ \\
\hline
\end{tabular}

urban households). In this latter case, the result implies that a SNAP-receiving household could afford to spend more on a better apartment, for example, than it could before.

Table 4 also shows that SNAP households increase spending on food away from home (by $\$ 63$ for rural households and $\$ 53$ for urban households), but this is small enough that it may not be significant. Other studies have found that SNAP reduces expenditure on food away from home or has no effect (Hoynes and Schanzenbach 2009; Burney 2018; Saksena et al. 2018; Tiehen, Newman, and Kirlin 2017; Beatty and Tuttle 2015; Kim 2016).

The bottom of Table 4 shows the total change in effective spending. Rural SNAP households experience the greatest increase in spending under SNAP, with a gain of $\$ 3,351$ per year. Urban SNAP households, meanwhile, increase 
spending by $\$ 2,817$. The situation for higher-income non-SNAP households is somewhat different, as they spend $\$ 992$ and $\$ 1,083$ less in rural and urban areas, respectively, under SNAP. This is less than one percent of their spending, however, and is due to indirect effects such as income changes owing to the expansions and contractions of different sectors of the economy. By contrast, SNAP-receiving households increase their effective spending an average of 7 percent, so the program clearly has much more impact.

The program makes a relatively large difference for SNAP-receiving, as opposed to non-SNAP households, regardless of location and whether taxes associated with the program are included (as was discussed above). This is because SNAP benefits are concentrated among a relatively small number of people (approximately one in five) while the indirect effects of the program (manifested primarily through changing prices for goods and services) are distributed widely (Table 3). A further observation is that rural SNAP households benefit relatively more than urban SNAP households. This is explained mainly by the fact that rural households are larger on average $(2.2$ versus 1.8 people), but is also influenced by changes in income that arise from changes in economic activity. For example, according to the SAM, much of the earned income of low-income households is from sales of labor. Meanwhile, some industries are more labor-intensive than others, and these industries are differentially affected by the spending changes induced by SNAP. The pattern of changes are estimated to help rural households very slightly on net.

\section{Effects on Rural and Urban Production}

As a result of the shifts in consumption created by SNAP, there are changes in the prices and hence production of a wide variety of goods and services. Table 5 reports percentage changes in commodity prices, changes in economic activity, and changes in labor activity due to SNAP. For reporting purposes, Table 5 has a different aggregation of the 35 sectors than Table 4, since the former focuses on production. Looking first at the change in commodity prices, there is a small increase in prices for most of the sectors, including for agricultural and manufacturing activities and especially for food processing (which can be purchased with SNAP benefits when used as food at home). These changes do not exceed 0.301 percent, and in many cases are smaller.

The results concerning prices are largely consistent with previous studies. For example, in an early study, Martinez and Dixit (1992) found that food assistance programs similar in form to SNAP increase farm prices by less than 1 percent. Lusk (2015) found that for every dollar that taxpayers spend on SNAP, agricultural commodity prices rise by approximately one penny. Even though the methods of those studies are distinct, the results are highly consistent with those of this study. This provides some assurance regarding the robustness of this study's methods. 
Table 5. Changes in Production, Jobs and Prices due to SNAP

\begin{tabular}{|c|c|c|c|c|c|c|c|}
\hline & \multirow{2}{*}{$\begin{array}{l}\text { Change in } \\
\text { commodity } \\
\text { prices }(\%)\end{array}$} & \multicolumn{2}{|c|}{$\begin{array}{l}\text { Change in } \\
\text { value of output } \\
\text { (\$ million) }\end{array}$} & \multicolumn{2}{|c|}{$\begin{array}{c}\text { Change in } \\
\text { value of output } \\
(\%)\end{array}$} & \multicolumn{2}{|c|}{$\begin{array}{c}\text { Change in } \\
\text { labor activity } \\
\text { (\# jobs) }\end{array}$} \\
\hline & & Rural & Urban & Rural & Urban & Rural & Urban \\
\hline Food processing & 0.262 & 62.8 & 141.0 & 0.56 & 1.26 & 157 & 284 \\
\hline Dairy, meat, fish & 0.205 & 21.5 & 48.2 & 0.68 & 1.53 & 40 & 73 \\
\hline Fruit, vegetables & 0.280 & 19.3 & 43.3 & 0.50 & 1.12 & 55 & 100 \\
\hline Miscellaneous food & 0.301 & 22.0 & 49.5 & 0.50 & 1.12 & 61 & 111 \\
\hline Food services & -0.001 & -1.5 & -8.6 & -0.02 & -0.11 & -27 & -145 \\
\hline Alcohol and tobacco & 0.044 & 0.3 & 1.3 & 0.01 & 0.04 & 0 & 2 \\
\hline Farming & 0.110 & 41.6 & 36.7 & 0.63 & 0.55 & 391 & 506 \\
\hline Crop farming & 0.155 & 23.9 & 21.0 & 0.58 & 0.51 & 219 & 284 \\
\hline Animal husbandry & 0.133 & 13.3 & 11.7 & 0.96 & 0.85 & 124 & 161 \\
\hline Agriculture services & 0.044 & 4.4 & 3.9 & 0.34 & 0.30 & 47 & 61 \\
\hline Manufacturing & 0.042 & 8.6 & 170.9 & 0.01 & 0.20 & 41 & 335 \\
\hline Clothing & 0.039 & 0.0 & 0.4 & 0.00 & 0.06 & 0 & 2 \\
\hline Petroleum & 0.052 & 0.0 & 0.7 & 0.01 & 0.19 & 0 & 0 \\
\hline Durables & 0.031 & 7.2 & 143.1 & 0.01 & 0.29 & 33 & 270 \\
\hline Non-durables & 0.045 & 1.3 & 26.6 & 0.01 & 0.26 & 8 & 63 \\
\hline Wholesale and retail & -0.041 & -9.5 & -74.0 & -0.03 & -0.21 & -133 & -779 \\
\hline Transportation & 0.022 & 3.1 & 10.6 & 0.03 & 0.09 & 16 & 70 \\
\hline Finance \& insurance & 0.000 & -7.8 & -50.5 & -0.03 & -0.25 & -25 & -228 \\
\hline Housing & -0.021 & -7.5 & -48.2 & -0.03 & -0.17 & -21 & -132 \\
\hline Education & -0.018 & 0.0 & -1.2 & 0.00 & -0.01 & 0 & -3 \\
\hline Health & -0.033 & -9.2 & -69.0 & -0.04 & -0.30 & -85 & -561 \\
\hline Utilities & 0.013 & 2.1 & 10.2 & 0.03 & 0.13 & 3 & 19 \\
\hline Services & -0.029 & 0.0 & 0.3 & 0.00 & 0.02 & 36 & 200 \\
\hline Total or average & 0.027 & 82.9 & 119.4 & 0.086 & 0.095 & 354 & -433 \\
\hline
\end{tabular}

The third and fourth columns of Table 5 report the change in output for a given economic sector distinguished across rural and urban areas. Some urban sectors expand much more than their rural counterparts, while other urban sectors shrink much more than their rural counterparts. For example, food processing increases $\$ 141.0$ million in urban areas versus $\$ 62.8$ million in rural areas, and manufacturing increases $\$ 170.9$ million in urban areas versus $\$ 8.6$ million in rural areas. This is due to larger populations in urban areas and because most of this economic activity takes place in urban areas. 
The only sector for which rural areas have a larger change in magnitude is the farming sector ( $\$ 41.6$ versus $\$ 36.7$ million).

Urban areas lose disproportionately more from the reduction in spending in some service-related sectors. For example, wholesale and retail trade declines $\$ 74.0$ million in urban areas versus $\$ 9.5$ million in rural areas, and finance and insurance services decline $\$ 50.5$ million in urban areas versus $\$ 7.8$ million in rural areas. These reductions occur because resources are being drawn into the food sectors. Since they are all less than 1 percent, they should not be overemphasized. Yet the implication is that urban areas experience both the largest expansions and largest declines associated with SNAP. Despite their relative reliance on farming, rural areas end up having a smaller overall economic impact from SNAP (\$82.9 million) when compared to urban areas ( $\$ 119.4$ million).

Examination of the changes in percentage terms in Table 5 provides additional context to the patterns. First, the percentage change in value of output rises for most sectors under SNAP, but not for a number of services for which demand is more income-elastic. Second, urban areas both gain and lose disproportionately more in most cases, since urban areas are larger. For example, food processing increases in both areas but by only 0.56 percent in rural areas and by 1.26 percent in urban areas. Meanwhile, wholesale and retail services decline in both areas, but by only 0.03 percent in rural areas and by 0.21 percent in urban areas. With the exception of manufacturing, urban sectors are oriented towards the service sectors for which non-SNAP are more likely to reduce expenditures.

\section{Effects on Rural and Urban Labor Markets}

Employment provides an additional lens through which to envision the impact of SNAP on rural and urban areas. Table 5 reports SNAP's effects on jobs, including both part- and full-time jobs (which are not distinguished in the IMPLAN data). Starting with the food services row, it is seen that 145 food service jobs (e.g., restaurants) were lost in urban areas under SNAP, while 27 such jobs were lost in rural areas. Another sector that lost jobs was wholesale and retail trade, which shed 779 jobs in urban areas and 133 in rural areas. Other sectors drew in some of this labor. For example, the urban food processing sector gained 284 jobs and the rural food processing sector gained 157.

As with other measures of sector size in Table 5, urban areas experience the largest gains in jobs, and also the largest losses of jobs. However, while the value of output in urban areas rises under SNAP, urban areas have a net loss of jobs. Once all of the changes across industries are added up, it is found that the number of jobs in urban areas falls by 433 under SNAP, while the number of jobs in rural areas rises by 354 under SNAP. As indicated earlier, this need not be equal under labor market clearing since the latter is in value terms. 
Wages and the productivity of labor can vary by sector, and so there does not have to be perfect adding up in terms of jobs.

These changes are not large in percentage terms. One way to see this is in Table 2, which shows that the net changes are very small relative to the total number employed. Yet it is worth reemphasizing two characteristics of the results above. One is that urban economies are oriented relatively more towards services that are somewhat more labor intensive. Meanwhile, these are the very sectors that decline most under SNAP. This reduces labor employment in urban areas. A second reason is that the general equilibrium model allows for the fact that firms can substitute capital for labor, and vice versa, as different industries expand or contract. Due to these factors, the number of jobs in a given economic sector need not change in fixed proportion with the size of a given industry.

Further perspectives on the results are provided in Table 2. It shows that the base value of output (sales) in rural and urban areas are \$36,953.0 and $\$ 279,595.9$ million, respectively. Starting from this, SNAP is estimated to increase sales of firms in rural and urban regions by $\$ 24.5$ and $\$ 185.4$ million, respectively. This can be compared against the $\$ 1,189$ million worth of SNAP spending in the state.

Another useful summary measure for this study is the change per dollar of SNAP spending. Taking a ratio of the increased value of output (sales) to the amount of SNAP spending in the state, the estimated change in value of output per dollar of SNAP is $\$ 0.02$ in rural areas and $\$ 0.16$ in urban areas (Table 2). At the state level, a dollar of SNAP spending leads to $\$ 0.18$ higher value of output. These estimates are conditioned by the fact that labor and capital resources are constrained within the model and since the state is tied to other regions through trade. Imports from outside the region help meet consumer demands associated with SNAP. As a result, the net effect on regional economies is moderate.

\section{Limitations and Extensions}

As mentioned above, one limitation is that the endogenous nature of SNAP participation is not represented in this study. While the issue of participation versus non-participation is an important topic, it is beyond the scope of the study at hand. The emphasis here is on the funding that is recorded as being allocated.

Another issue not considered is the question of how individuals' willingness to work is affected by changes in SNAP benefits. In a review of the evidence, Moffitt (2002) concludes that programs such as SNAP have "little effect" on work disincentives while Hoynes and Schanzenbach (2012) find "modest" reductions in employment and hours worked due to SNAP. Investigation of this issue is important but would require data and methods quite distinct from those of this study. 
Another observation is that although a good amount of data was available to distinguish rural and urban areas, spending behavior across rural and urban households was not distinguished due to data limitations. For a given income level, rural and urban households are assumed to make adjustments in the same way. Households at different income levels do have distinct behavioral patterns.

It is also important to acknowledge that many model parameters were calibrated using historical data when SNAP was in place. The existence of the program at this time could have influenced the values of the calibrated parameters.

A further area for improvement would be to provide a finer level of regional disaggregation by way of rural-urban continuum codes or Beale codes. For example, rural areas could be further disaggregated according to population and adjacency to urban areas.

\section{Conclusions and Policy Implications}

The objective of this study has been to quantify SNAP's effects on rural and urban areas of a regional economy with focus on how SNAP impacts economic sectors and labor markets. By covering the food expenses of lowor no-income households, SNAP allows them to increase food and non-food expenditures by approximately seven percent in both rural and urban areas. These expenditure changes draw resources from other parts of the economy, creating price and income changes for all households in the economy. One result is that across rural and urban areas alike, higher-income households that do not use SNAP experience a slight 1-percent reduction in spending.

The shift in rural and urban consumption of food causes agriculture and food prices to rise slightly. Food and agricultural production expands in rural and urban areas, but most of the expansion of the agricultural sector is in rural areas, while most of the expansion in food processing is in urban areas.

Expansion of food and agricultural sectors requires resources such as labor that are drawn from other sectors. Urban areas have higher concentrations of service sectors that are labor intensive, and some of these sectors contract slightly under SNAP. On net, SNAP is estimated to cause a 432 job loss in urban areas and a 354 job gain in rural areas. In a state estimated to have $2,188,001$ jobs, these changes are very minor.

A policy implication is that the effects on higher-income taxpayers and nonfood businesses are not large enough in an economic sense to be used as a justification for or against the program. Policymakers should not assume that the budgetary requirements of SNAP have strong welfare effects on taxpayers.

On the supply side of the economy, SNAP does have place-specific effects. Both the largest increases and decreases in the economy occur in urban areas. Averaging over the changes, a dollar's worth of SNAP translates into $\$ 0.16$ and $\$ 0.02$ extra economic production in urban and rural areas, respectively. A policy implication that emerges from the study is that SNAP is at best a 
moderate way to support American agriculture, which is one of the stated missions of SNAP. SNAP's salient effect is to provide benefits to low- or noincome urban and rural households that experience economic distress.

The findings described above did not vary under different assumptions about how SNAP is funded. While the costs of SNAP are often a source of political controversy, this aspect was found to matter very little because any taxes required for the program are diffused across numerous taxpayers, making any tax virtually undetectable to a given taxpayer.

\section{Acknowledgements}

This research was supported financially by USDA Economic Research Service cooperative agreement number 58-6000-4-0017 (SNAP and the Rural Economy) as well as Oregon State University. Feedback from participants at several conferences and seminars is appreciated.

\section{References}

Barrett, C.B. 2002. "Food Security and Food Assistance Programs." In B.L. Gardner and G. Rausser (eds.). Handbook of Agricultural Economics 2. 2103-2190. Elsevier.

Beatty, T.K.M., and C.J. Tuttle. 2015. "Expenditure Response to Increases in In-Kind Transfers: Evidence from the Supplemental Nutrition Assistance Program." American Journal of Agricultural Economics 97(2):390-404.

Bernat, A., and K. Hanson. 1995. "Regional Impacts of Farm Programs: A Top-Down CGE Analysis." The Review of Regional Studies 25(3):331-350.

Breunig, R., and I. Dasgupta. 2005. "Do Intra-Household Effects Generate the Food Stamp Cash-Out Puzzle?" American Journal of Agricultural Economics 87(3):552-568.

Bureau of Economic Analysis. 2019. "Regional Economic Accounts. Bureau of Economic Analysis." Available at https://www.bea.gov/regional/index.htm (accessed January 2019).

Burney, S. 2018. "In-Kind Benefits and Household Behavior: The Impact of SNAP on FoodAway-from-Home Consumption.” Food Policy 75:134-146.

Center on Budget and Policy Priorities (CBPP). 2016. Introduction to the Supplemental Nutrition Assistance Program (SNAP). Center on Budget and Policy Priorities, Washington, DC.

Cuffey, J., T.K.M. Beatty, and L. Harnack. 2016. "The Potential Impact of Supplemental Nutrition Assistance Program (SNAP) Restrictions on Expenditures: A Systematic Review." Public Health Nutrition 19(17):3216-3231.

Hanson, K., E. Golan, S. Vogel, and J. Olmsted. 2002. Tracing the Impacts of Food Assistance Programs on Agriculture and Consumers: A Computable General Equilibrium Model. Report no. 18, Economic Research Service, U.S. Department of Agriculture, Washington, DC.

Hanson, K., and V. Oliveira. 2009. Economic Linkages between the WIC Program and the Farm Sector. Economic Brief no. 12, Economic Research Service, U.S. Department of Agriculture, Washington, DC.

Holland, D., L. Stodick, and S. Devadoss. 2010. Documentation for the Idaho-Washington CGE Model. Unpublished document, Washington State University, Pullman, WA.

Hoynes, H.W., and D.W. Schanzenbach. 2009. "Consumption Responses to In-Kind Transfer: Evidence from the Introduction of the Food Stamp Program." American Economic Journal: Applied Economics 1(4):109-139. 
2012. "Work Incentives and the Food Stamp Program." Journal of Public Economics 96 (1-2):151-162.

IMPLAN. 2012. "Data and Software." Huntersville, NC. Available at www.implan.com (accessed June 2013.)

Kim, J. 2016. "Do SNAP Participants Expand Non-Food Spending When They Receive More SNAP Benefits? Evidence from the 2009 SNAP Benefits Increase." Food Policy 65:9-20.

Klerman, J.A., and C. Danielson. 2016. "Can the Economy Explain the Explosion in the Supplemental Nutrition Assistance Program Caseload? An Assessment of the Locallevel Approach." American Journal of Agricultural Economics 98(1): 92-112.

Levedahl, J.W. 1995. "A Theoretical and Empirical Evaluation of the Functional Forms Used to Estimate the Food Expenditure Equation of Food Stamp Recipients." American Journal of Agricultural Economics 77(4):960-968.

Löfgren, H., S. Robinson, and R.L. Harris. 2002. A Standard Computable General Equilibrium (CGE) Model in GAMS. International Food Policy Research Institute (IFPRI), Washington, DC.

Lusk, J.L. 2015. "Distributional Effects of Selected Farm and Food Policies: The Effects of Crop Insurance, SNAP, and Ethanol Promotion." Mercatus Working Paper, Mercatus Center at George Mason University, Arlington, VA.

Martinez, S.W., and P.M. Dixit. 1992. Domestic Food Assistance Programs: Measuring the Benefits to Producers. Economic Research Service, U.S. Department of Agriculture, Washington, DC.

McCullough, M., D.W. Holland, K. Painter, L. Stodick, and J. Yoder. 2011. "Economic and Environmental Impacts of Washington State Biofuel Policy Alternatives," Journal of Agricultural and Resource Economics 36(3):615-629.

Moffitt, R.A. 2002. "Welfare Programs and Labor Supply". In A.J. Auerbach and M. Feldstein (eds.). Handbook of Public Economics. Elsevier.

Muhammad, A., J.L. Seale Jr., B. Meade, and A. Regmi. 2011. International Evidence on Food Consumption Patterns: An Update Using 2005 International Comparison Program Data. Economic Research Service, U.S. Department of Agriculture, Washington, DC.

Pender, J., J. Young, J.E. Todd, and C. Miller. 2019. The Impacts of Supplemental Nutrition Assistance Program Redemptions on County-Level Employment. Economic Research Service ERR-263, U.S. Department of Agriculture, Washington, DC.

Reimer, J.J., and T.W. Hertel. 2004. "Estimation of International Demand Behavior for Use with Input-Output Based Data." Economic Systems Research 16(4): 347-366.

Reimer, J.J., and S.A. Weerasooriya. 2019. "Macroeconomic Impacts of U.S. Farm and Nutrition Programs" Journal of Agricultural and Resource Economics 44(3):624-645.

Reimer, J.J., S.A. Weerasooriya and T.T. West. 2015. "How Does the Supplemental Nutrition Assistance Program Affect the United States Economy?" Agricultural and Resource Economics Review 44(3): 233-252.

Saksena, M.J., A.M. Okrent, T.D. Anekwe, C. Cho, C. Dicken, A. Effland, H. Elitzak, J. Guthrie, K.S. Hamrick, J. Hyman, Y. Jo, B.H. Lin, L. Mancino, P.W. McLaughlin, I. Rahkovsky, K. Ralston, T. A. Smith, H. Stewart, J. Todd, and C. Tuttle. 2018. America's Eating Habits: Food Away from Home. EIB-196, Economic Research Service, U.S. Department of Agriculture, Washington, DC.

Tiehen, L., C. Newman, and J.A. Kirlin. 2017. The Food-Spending Patterns of Households Participating in the Supplemental Nutrition Assistance Program: Findings from USDA's FoodAPS. EIB-176, Economic Research Service, U.S. Department of Agriculture, Washington, DC.

U.S. Census Bureau. 2019. "Survey of Income and Program Participation (SIPP)." Available at http://www.census.gov/sipp/ (accessed January 2019).

U.S. Department of Agriculture Economic Research Service. 2019 "Supplemental Nutrition Assistance Program (SNAP) Data System." Available at http://www.ers.usda.gov/dataproducts/supplemental-nutrition-assistance-program-(snap)-data-system.aspx (accessed January 2019). 
U.S. Department of Agriculture Food and Nutrition Service. 2014. State Supplemental Nutrition Assistance Program Participation Rates in 2011. Food and Nutrition Service, U.S. Department of Agriculture, Washington, DC.

— 2019. "Supplemental Nutrition Assistance Program (SNAP) Program Data." Available at http://www.fns.usda.gov/pd/overview (accessed January 2019).

Waters, E.C., D.W. Holland, and B.A. Weber. 1997. "Economic Impacts of a Property Tax Limitation: A Computable General Equilibrium Analysis of Oregon's Measure 5." Land Economics 73(1):72-89. 